\title{
Papillary tumor of the pineal region: A case report and review of the literature
}

\author{
XIAOMIN HUA $^{1 *}$, PING YANG ${ }^{2 *}$, MING ZHANG $^{3}$, YUDAN ZHAO $^{1}$ and BIN WANG ${ }^{1}$ \\ ${ }^{1}$ Department of Microbiology, Qingdao University Medical College, Qingdao, Shandong 266071; ${ }^{2}$ Department of Pathology, \\ Yantai Yuhuangding Hospital, Yantai, Shandong 264000; ${ }^{3}$ Department of Anatomy, Qingdao University Medical College, \\ Qingdao, Shandong 266071, P.R. China
}

Received April 13, 2015; Accepted July 14, 2015

DOI: $10.3892 / \mathrm{etm} .2015 .2696$

\begin{abstract}
Papillary tumor of the pineal region (PTPR) was first described as a distinct tumor entity in 2003 and was introduced into the World Health Organization classification of central nervous system tumors in 2007. This tumor is rare and, to the best of our knowledge, only 7 cases have been reported in children $<16$ years of age, while the youngest documented patient was a 15-month-old boy. The present study reported a case of PTPR in a 10-year-old girl who underwent magnetic resonance imaging and surgical resection of tumors. Histological and immunohistochemical staining results were presented. Patients with PTPR require long-term follow-up, and the patient of the present study has continued to do well, with no recurrence of the tumor at the 15-month follow-up examination. In addition, a review of the literature on this unusual neoplasm was performed, along with discussion of their differential diagnosis.
\end{abstract}

\section{Introduction}

Papillary tumor of the pineal region (PTPR) was originally described as a distinct clinicopathological entity by Jouvet et al in 2003 (1). In 2007, PTPR was included in the World Health Organization classification of central nervous system tumors (2). PTPR does not arise from the pineal gland itself, but originates from specialized cytokeratin-positive and nestin-positive ependymal cells that are derived from the subcommissural organ (3-5). Tumors of the pineal region are rare lesions, accounting for only $1 \%$ of all intracranial

Correspondence to: Professor Bin Wang, Department of Microbiology, Qingdao University Medical College, 308 Ningxia Road, Qingdao, Shandong 266071, P.R. China

E-mail: wangbin532@126.com

${ }^{*}$ Contributed equally

Key words: papillary tumor of the pineal region, pineal region, immunohistochemistry, central nervous system, differential diagnosis tumors (6). PTPR have morphological features in common with a number of other papillary-like tumors that occur in the pineal region, including pineal parenchymal neoplasms, choroid plexus papilloma, papillary ependymoma, metastatic papillary carcinomas, papillary meningioma and germ cell tumors $(5,7)$, which complicates the clinical diagnosis of PTPR. Clinical presentation most often includes headache and obstructive hydrocephalus. Microscopic evaluation often demonstrates a lesion with papillary areas lined by epithelioid tumors with eosinophilic cytoplasm, and numerous cells exhibiting clear or vacuolated cytoplasm. Perivascular and true rosettes may be identified (8). The natural history and optimal treatment of PTPR remain controversial (9) and Kaplan-Meier analysis provided a 5 year survival estimate of $73 \%$ (10). The present study reports the case of a 10 -year-old patient that underwent magnetic resonance imaging (MRI) and surgical resection of tumors of the pineal region. The final diagnosis of PTPR was based on the morphological features of the tumor cells and the results of immunohistochemical staining. A written informed consent was obtained from the patient's family.

\section{Case report}

A 10-year-old girl presented with one-year history of right eye strabismus accompanied by diplopia, with no apparent cause. The patient was treated with traditional Chinese medicine in a local hospital and the diplopia symptoms were alleviated, while the strabismus symptoms persisted. One month prior to presentation, the patient suffered from an irregular intermittent headache, particularly in the lateral and top areas of the forehead. During this period, the patient additionally experienced intermittent nausea and vomiting. For further evaluation, the patient was admitted to the Affiliated Hospital of Qingdao University (Qingdao, China) in March 2014. The results of a physical examination conducted at the point of patient admission to the hospital were unremarkable with the exception of the right eye strabismus. Further MRI scans demonstrated a heterogeneously-enhanced and well-defined space-occupying lesion with limited cystic components in the pineal region (Fig. 1). The patient was diagnosed with hydrocephalus and abnormal cerebral aqueduct, which was considered to be a tumor. 

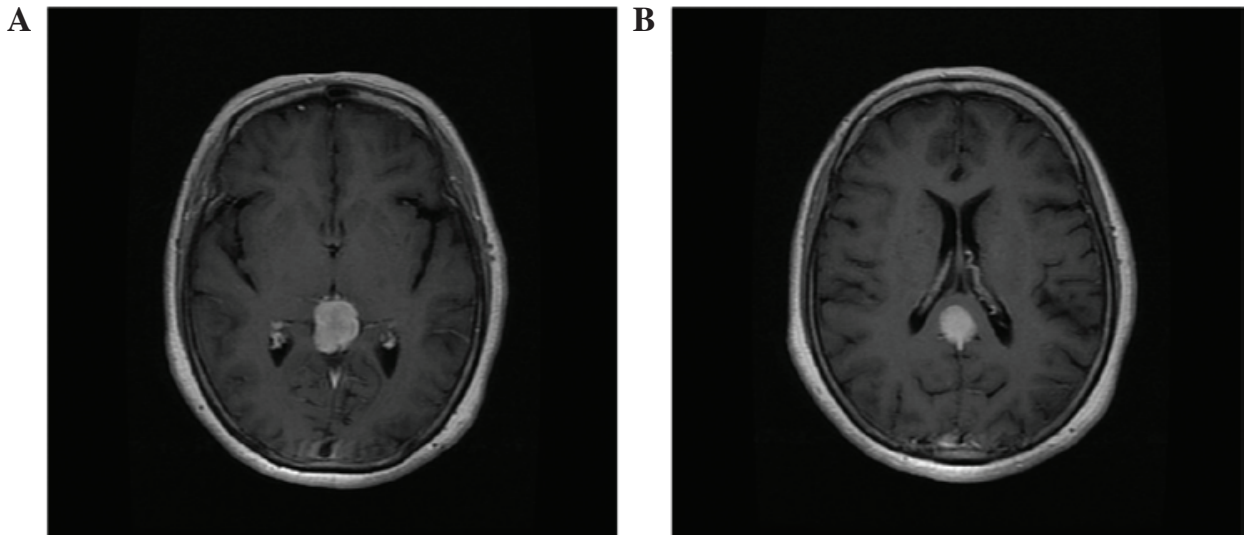

Figure 1. Axial magnetic resonance images demonstrating a well-circumscribed space-occupying lesion in the pineal region. (A) T1-weighted axial MRI of a well-circumscribed solid pineal tumor. (B) T1-weigthed axial MRI of a tumor and the ministry of corpus collosum. MRI, magnetic resonance imaging.
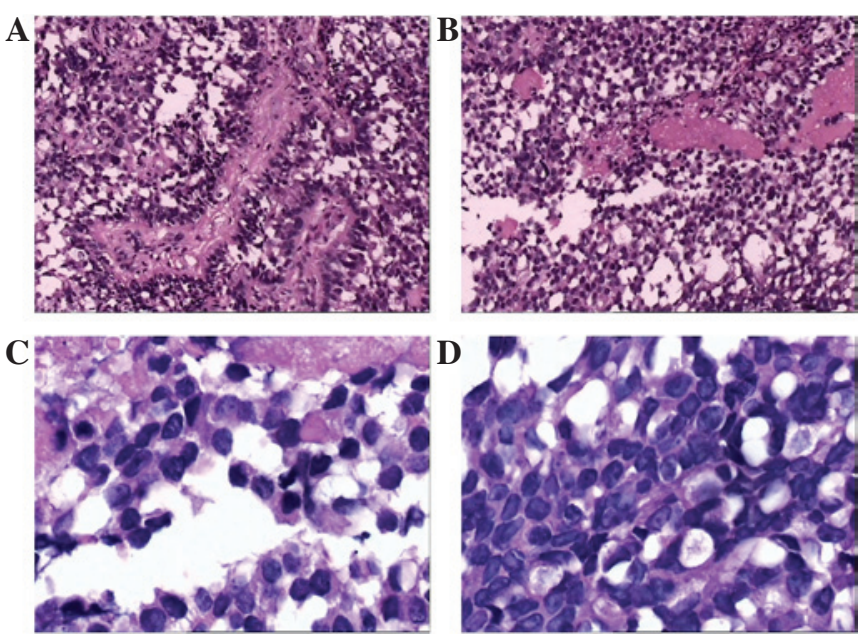

Figure 2. Hematoxylin and eosin staining revealing the papillary features of the tumor cells. (A and B) Sections of the tumor exhibited papillary structures and a palisade arrangement surrounding the vascular pseudo-stratified columnar epithelium (magnification, $\mathrm{x} 100$ ). (C and D) The cytoplasm was hyperchromatic and exhibited irregular nuclei (magnification, $\mathrm{x} 400$ ).

The tumor was removed via a suboccipital transtentorial approach (11). During surgery, the tumor appeared grayish, soft, well-circumscribed and markedly vascular, exhibiting adhesion to the deep venous system and strong adhesion to the corpora quadrigemina. The majority of the tumor was succesfully removed, and the patient underwent an endoscopic third ventriculostomy for hydrocephalus management.

Microscopic examination revealed that parts of the tumor exhibited papillary structures and a palisade arrangement surrounding the vascular pseudostratified columnar epithelium was observed. Examination of hematoxylin and eosin-stained sections showed that the cells demonstrated papillary growth patterns. The cytoplasm was hyperchromatic and the nuclei were slightly irregular (Fig. 2). In addition, immunohistochemical staining revealed marked immunoreactivity for S100-protein, neuronal specific enolase, CAM5.2 and cytokeratin $8 / 18$, while the tumor was focally immunoreactive for synaptophysin; however, the tumor was found to be negative for glial fibrillary acidic protein (GFAP) and epithelial membrane antigen. The Ki67 proliferative index at this initial resection
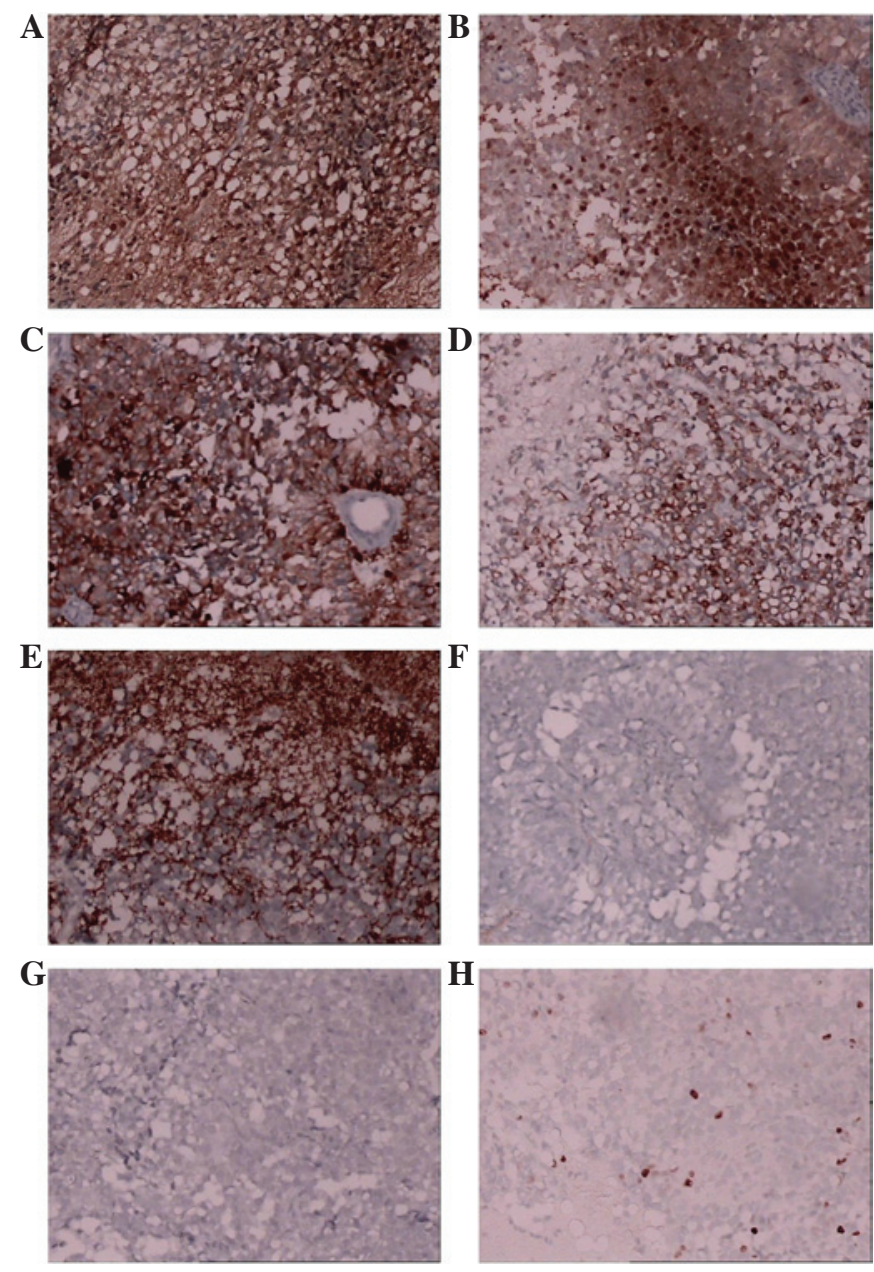

Figure 3. Micrographs demonstrating positive immunohistochemical staining for (A) S-100, (B) neuron-specific enolase, (C) Cam5.2, (D) CK8-18 and (E) Syn, and negative staining for (F) glial fibrillary acidic protein and (G) epithelial membrane antigen. (H) Approximately 5\% of the tumor cells were positive for Ki67.

was $\sim 5 \%$ (Fig. 3). On the basis of these features, a diagnosis of PTPR was rendered. Postoperatively, the patient continues to do well, and no recurrent tumor was found at the 15-month follow-up examination. 


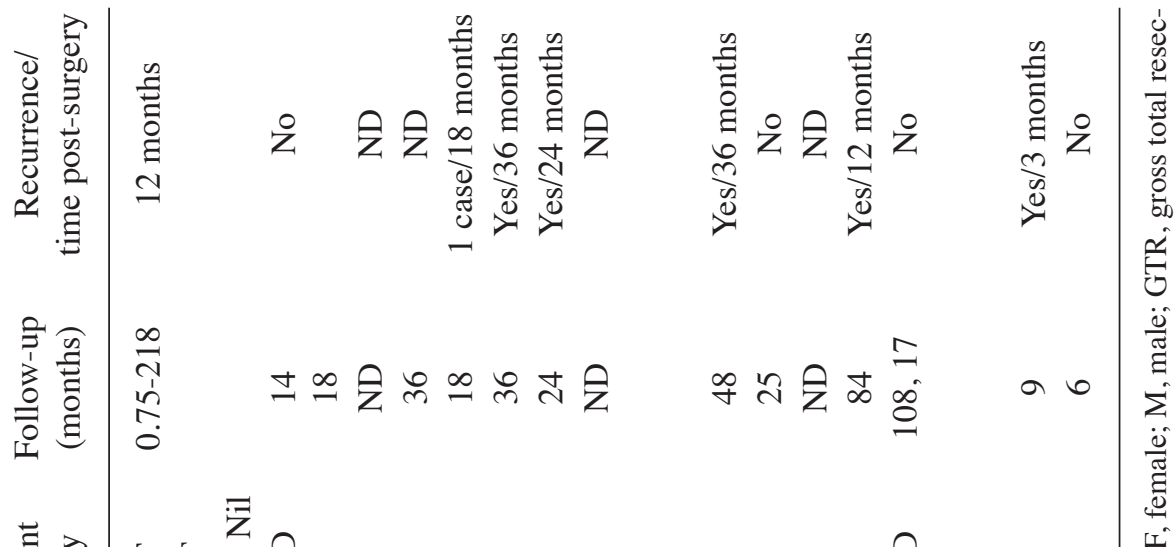

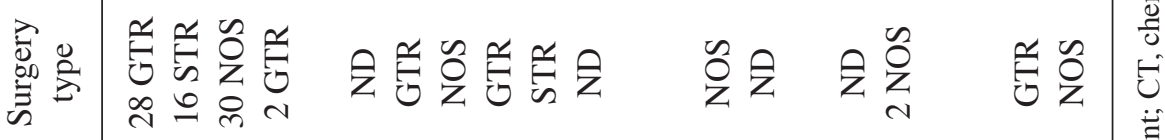

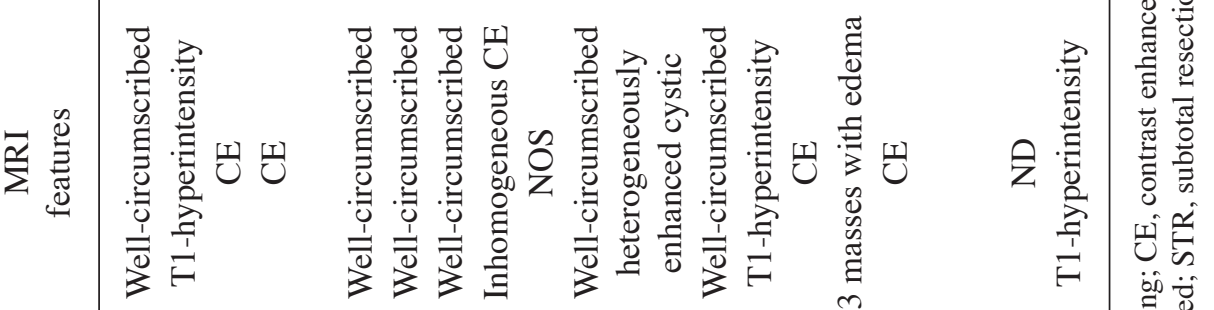

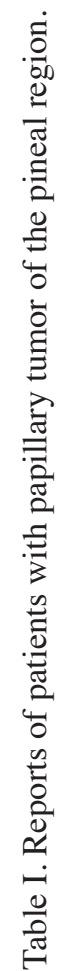

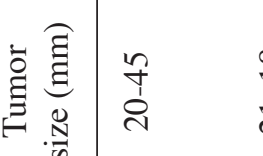

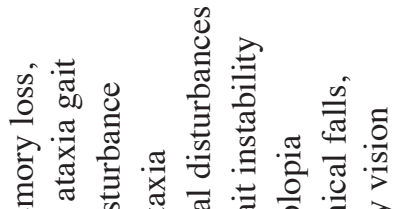

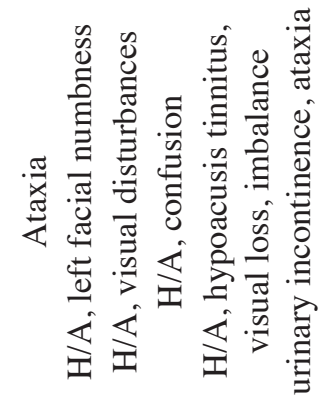

نे

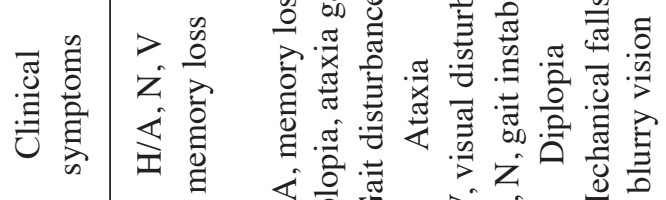

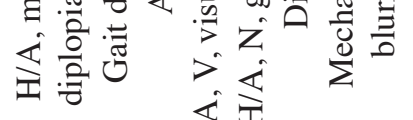

这王

之

范 
Table II. Clinicopathological characteristics of patients with papillary tumor of the pineal region in the reviewed literature.

\begin{tabular}{lcc}
\hline Characteristic & Total cases, $n$ & $\begin{array}{c}\text { Percentage of } \\
\text { the cases, } \%\end{array}$ \\
\hline Age, years & & \\
$\leq 16$ & 7 & 7.53 \\
$16-65$ & 84 & 90.32 \\
$\geq 65$ & 2 & 2.15 \\
Gender & & \\
Female & 46 & 49.46 \\
Male & 47 & 50.54 \\
Size, mm & & 10.71 \\
$\leq 10$ & 3 & 89.29 \\
$>10$ & 25 & \\
Recurrence & & 32.61 \\
Yes & 31 & \\
No & 15 & \\
\hline
\end{tabular}

Recurrence and size were not provided for all cases due to insufficient data.

\section{Discussion}

The term 'PTPR' is based on the histopathological description of a tumor characterized by a papillary pattern, rosettes and pseudorosettes (11). Other tumors of the pineal region manifested by papillary features include pineal parenchymal neoplasms, choroid plexus papilloma, papillary ependymoma, metastatic papillary carcinomas, papillary meningioma and germ cell tumors. However, pineal parenchymal tumors, meningiomas and germ cell tumors rarely display papillary features (12). The immunohistochemical characteristics of PTPR include variable immunoreactivity for cytokeratin and S-100 protein, and complete absence of immunoreactivity for GFAP; therefore, GFAP staining aid in distinguishing this neoplasm from an ependymoma $(13,14)$. Choroid plexus papilloma rarely occurred in the posterior third ventricle. Therefore, in the present study, ultrastructural and immunohistochemical analyses were used to distinguish this type of papillary tumor from other papillary-like tumors that occur in the region, and a final histological diagnosis of PTPR was confirmed.

PTPR is an uncommon type of neoplasm and, to the best of our knowledge, only 93 cases have been reported thus far (14-25). Table I summarizes 93 cases of patients with PTPR (14-25), including 74 cases described by Poulgrain et al in 2011 (15) and 19 cases reported after 2011 (8-25). The 93 previously reported cases include a wide range of ages. The youngest patient was a 15-month-old boy (16) and the oldest was a 67-year-old female (15). In addition, 7 cases have been reported in children younger than 16 years (Table II). The present study reported a case of PTPR in a 10-year-old girl, with the proportion of children being $7.53 \%$. Notably, the incidence rates of PTPR in elderly patients are low and, to the best of our knowledge, only 2 cases have been reported in patients older than 65 years (15). By contrast, PTPR is more common among individuals aged $\sim 30$ years (7). Almost no difference was detected in PTPR prevalence between males and females in the cases described (47 males vs. 46 females). Tumors ranged between 5 and $49 \mathrm{~mm}$ in size. The recurrence rate was high $(67.39 \%)$ and Kaplan-Meier analysis provided a 5-year survival estimate of $73 \%$ (10). In the present study we report a rare case of PTPR in a 10- year old girl who underwent a total tumour resection with no recurrence at the 15-month follow-up examination.

Clinical data concerning PTPR is limited and its pathogenesis is unknown. PTPR is frequently misdiagnosed as ependymoma or choroids plexus papilloma. However, the diagnostic criteria of certain postulated papillary-like tumors have been revised, and a more complete understanding of this tumor may be obtained. The present study reported a case of PTPR in a 10 year-old girl who suffered from an irregular intermittent headache, particularly in the lateral and top areas of the forehead. The patient were treated with Chinese medicine which alleviated the diplopia symptoms. Similarly to previous reports they underwent magnetic resonance imaging and surgical tumor resection, and continues to have a positive postoperative outcome. These results along with the data from previous studies indicate that total tumor resection is the optimal treatment guideline.

\section{Acknowledgements}

This study was supported by a National Nature Science Foundation grant (no. 81471958).

\section{References}

1. Jouvet A, Fauchon F, Liberski P, Saint-Pierre G, Didier-Bazes M, Heitzmann A, Delisle MB, Biassette HA, Vincent S, Mikol J, et al: Papillary tumor of the pineal region. Am J Surg Pathol 27: 505-512, 2003.

2. Louis DN, Ohgaki H, Wiestler OD, Cavenee WK, Burger PC, Jouvet A, Scheithauer BW and Kleihues P: The 2007 WHO classification of tumours of the central nervous system. Acta Neuropatholo 114: 97-109, 2007.

3. Li J, Recinos PF, Orr BA, Burger PC, Jallo GI and Recinos VR: Papillary tumor of the pineal region in a 15-month-old boy. J Neurosurg Pediatr 7: 534-538, 2011.

4. Montange MF, Vasiljevic A, Champier J and Jouvet A. Papillary tumor of the pineal region: Histopathological characterization and review of the literature. Neurochirurgie 61: 138-142, 2014.

5. Vandergriff C, Opatowsky M, O'Rourke B and Layton K: Papillary tumor of the pineal region. Proc (Bayl Univ Med Cent) 25: 78-79, 2012.

6. Bruce JN and Stein B: Pineal tumors. Neurosurg Clin N Am 1: 123-138, 1990.

7. Kawahara I, Tokunaga Y, Yagi N, Iseki M, Abe K and Hayashi T: Papillary tumor of the pineal region. Neurol Med Chir (Tokyo) 47: 568-571, 2007.

8. Rickard KA, Parker JR, Vitaz TW, Plaga AR, Wagner S and Parker JC Jr: Papillary Tumor of the Pineal Region: Two Case studies and a review of the literature. Ann Clin Lab Sci 41: 174-181, 2011.

9. Inoue T, Kumabe T, Kanamori M, Sonoda Y, Watanabe M and Tominaga T: Papillary tumor of the pineal region: A case report. Brain Tumor Pathol 25: 85-90, 2008.

10. Boco T, Aalaei S, Musacchio M, Byrne R and Cochran E: Papillary tumor of the pineal region. Neuropathology 28: 87-92, 2008.

11. Junior GV, Dellaretti M, de Carvalho GT, Brandão RA, Mafra A and de Sousa AA: Papillary tumor of the pineal region. Brain Tumor Patholo 28: 329-334, 2011.

12. Chang AH, Fuller GN, Debnam JM, Karis JP, Coons SW, Ross JS and Dean BL: MR imaging of papillary tumor of the pineal region. AJNR Am J Neuroradio 29: 187-189, 2008. 
13. Kawahara I, Tokunaga Y, Yagi N, Iseki M, Abe K and Hayashi T: Papillary tumor of the pineal region. Neurolo Med Chir (Tokyo) 47: 568-571, 2007.

14. Sun IS, Kirollos R and Santarius T: No 5-ALA fluorescence seen in a recurrent papillary tumour of the pineal region (PTPR). Acta Neurochir (Wien) 157: 215-216, 2015.

15. Poulgrain K, Gurgo R, Winter C, Ong B and Lau Q: Papillary tumour of the pineal region. J Clin Neurosci 18: 1007-1017, 2011.

16. Li J, Recinos PF, Orr BA, Burger PC, Jallo GI and Recinos VR: Papillary tumor of the pineal region in a 15 -month-old boy. J Neurosurg Pediatr 7: 534-538, 2011.

17. Santoro A, D'Elia A, Fazzolari B, Santoro F, Antonelli M, Giangaspero F, Brogna C, Lenzi J, Frati A and Salvati M: Four-year clinical and neuroradiological follow-up of a papillary tumor of the pineal region. Neurol Sci 33: 931-935, 2012.

18. Matyja E, Grajkowska W, Nauman P and Bonicki W: Histopathological patterns of papillary tumour of the pineal region. Folia Neuropathol 49: 181-190, 2011.

19. Abela L, Rushing EJ, Ares C, Scheer I, Bozinov O, Boltshauser E and Grotzer MA: Pediatric papillary tumors of the pineal region: To observe or to treat following gross total resection? Childs Nerv Syst 29: 307-310, 2013.
20. Ishida A, Shibuya M, Komori T, Nobusawa S, Niimura K, Matsuo S and Hori T: Papillary tumor of the pineal region: A case involving isocitrate dehydrogenase (IDH) genotyping. Brain Tumor pathol 30: 45-49, 2013.

21. Magalhães J, Rostad S, Foltz G, Pytel P and Rodriguez FJ: Cellular pleomorphism in papillary tumors of the pineal region. Brain Tumor Pathol 30: 93-98, 2013.

22. Patel SK, Tomei KL, Christiano LD, Baisre A and Liu JK: Complete regression of papillary tumor of the pineal region after radiation therapy: Case report and review of the literature. J Neurooncol 107: 427-434, 2012.

23. Vandergriff C, Opatowsky M, O'Rourke B and Layton K: Papillary tumor of the pineal region. Proc (Bayl Univ Med Cent) 25: 78-79, 2012.

24. Koziarski A, Grala B and Skrobowska E: Papillary tumor of the pineal region. Report of two cases and literature review. Neurol Neurochir Pol 48: 356-362, 2014.

25. Rosa Junior M, da Rocha AJ, Zanon da Silva A and Rosemberg S: Papillary tumor of the pineal region: MR Signal intensity correlated to histopathology. Case Rep Neurol Med 2015: 315095, 2015. 